\title{
Parental consent for newborn screening in southern Taiwan
}

\author{
M-C Huang, C-K Lee, S-J Lin, I-C Lu
}

J Med Ethics 2005;31:621-624. doi: 10.1136/jme.2004.010074

See end of article for authors' affiliations .....................

Correspondence to: M-C Huang, Department of Nursing, National Cheng Kung University, 1 University Rd, Tainan 701, Taiwan ROC; meay@mail. ncku.edu.tw

Received 12 July 2004

In revised form

4 February 2005

Accepted for publication

19 February 2005 logies, many genetic/metabolic disorders can be detected Objects: With the advent of genetic technologies, many genetic/metabolic disorders can be detected
asymptomatically but might be untreatable, and the benefits and risks of screening for them are not fully known. The purpose of this study is to explore current practice with regard to the parental consent process in newborn screening (NBS).

Design: Staff in 23 obstetric clinics/hospitals that conduct NBS in one city of southern Taiwan were interviewed. Using content analysis, 15 interview transcripts, eight completed questionnaires, and other relevant documents from the 23 clinics/hospitals were analysed to reveal the framework of the parental consent process in NBS in southern Taiwan.

Main measures: Three categories - informed consent, informed dissent, and no informed/consent-were developed to analyse the parental consent process in NBS.

Results: The parental consent procedures in NBS and the quality of the information provided before obtaining consent vary widely. Because the traditional NBS was incorporated into routine paediatric practices in most clinics/hospitals, the most frequently encountered consent model is "informed dissent" $(60.9 \%)$ and "no informed/consent" $(30.4 \%)$; while an "informed consent" model (45.5\%) is the frequent model for screening rare metabolic/genetic disorders.

Conclusions: Specific guidelines to regulate the parental consent process for NBS are essential. Further studies should investigate parental responses to NBS, taking these as the basis on which to establish an informed consent model in Taiwan.
1 nformed consent is one of the basic elements of medical ethics and the professional-patient relationship. Fully informed consent is a fundamental right of subjects in clinical interactions and is essential to ensure that they and/ or their families receive sufficient appropriate and understandable information to make a balanced judgment of risks and benefits. ${ }^{12}$ Newborn screening (NBS) is aimed at the early identification of selected genetic/metabolic diseases and could eliminate or reduce associated mortality, morbidity, and disability through appropriate and timely intervention. ${ }^{13-6}$ Because of the benefits of NBS, it is now seen as either routine or mandatory if affected newborns are to be treated quickly and competently. ${ }^{48}$

Because parents are presumed to make the best judges of what is in the best interest of their newborns, parental consent is sought for healthcare decisions to do with newborns. Thus, parents are the legitimate decision makers for their newborns. ${ }^{148}$ The arguments supporting parental consent for NBS assert that testing without their consent is assault. Obtaining parental consent for NBS demonstrates respect for the family and serves a valuable educational role. On the other hand, the primary arguments against requiring parental consent for NBS are that obtaining consent is time consuming and screening is beneficial for the newborn's health. Additionally, it must be said that sometimes consent is obtained in a merely perfunctory way with the result that it is actually uninformed consent. ${ }^{149}$

Consistent with the recent report of the Newborn Screening Task Force (1999), the American Academy of Pediatrics (AAP) recommends that informed consent in this context emphasises the importance of conversation in achieving consensus but need not involve a signed consent form. ${ }^{35}$ Throughout the process, the parents should be informed about what tests are offered and why follow up may be necessary and timely. ${ }^{4}$ Furthermore, if an informed consent process promotes more thorough understanding of the implications of the tests, slow or inappropriate responses to positive results may decrease. ${ }^{5}$ The World Health Organisation (WHO) Meeting on Ethical Issues in Medical Genetics (1997) recommends that NBS be mandatory and free of charge, if early diagnosis and treatment will benefit the newborn. It also says, however, that NBS should be preceded by adequate information about the purpose and possible outcomes of screening and potential choices to be made. $^{10}$

In Taiwan, mass newborn screening for five genetic/ metabolic disorders, including glucose-6-phosphate dehydrogenase deficiency (G-6-PD deficiency); congenital hypothyroidism; phenylketonuria; homocystinuria, and galactosemia started in 1985 when the genetic health law was implemented. ${ }^{11}$ Currently, three NBS centres, including the NBS centre at the National Taiwan University (NTU), the Chinese Foundation of Health (CFOH), and the Taipei Institute of Pathology (TIP), screen for the five traditional disorders, plus congenital adrenal hyperplasia (CAH). They also use tandem mass spectrometry (Tandem MS) to screen for over 20 rare metabolic/genetic disorders. The last two items are voluntary, and government does not cover the cost of those two screenings.

With the development of genetic tests, many genetic/ metabolic disorders can be detected asymptomatically but they might not be treatable. Although such tests would not benefit the affected newborns and might result in discrimination in the area of health insurance, they might at least serve to inform parents earlier about their future reproductive risks. ${ }^{346}$ Therefore, it can be seen that current NBS faces possible challenges of both an ethical and a legal nature. ${ }^{8}$ Because the parental consent model for current NBS is rarely examined, this study was set up to explore the current

Abbreviations: $\mathrm{CAH}$, congenital adrenal hyperplasia; $\mathrm{CFOH}$, Chinese Foundation of Health; Tandem MS, mass spectrometry; NBS, newborn screening; NTU, National Taiwan University; TIP, Taipei Institute of Pathology 
practices with regard to the obtaining of parental consent for NBS in order to provide improved public health policy in the future.

\section{METHODS \\ Subjects}

Of the 23 obstetric clinics/hospitals providing NBS services in Tainan City, 14 of them are on contract to the NBS centre at NTU, and nine are on contract to CFOH. All the clinics/ hospitals in the $\mathrm{CFOH}$ system provide screening for rare metabolic/genetic disorders via Tandem MS. Because NTU has not made this service available to all clinics/hospitals during the period of data collection, only two of the 14 employ this screening, giving a total of 11 clinics/hospitals that provide NBS for rare metabolic/genetic disorders in this study. All 23 clinics/hospitals provide the traditional five item NBS and CAH screening tests.

Each of the 23 obstetric clinics/hospitals recommended one or two representatives or senior staff members, whose work related to NBS services, to be the interviewees or questionnaire responders. All subjects were interviewed face to face or via telephone after their consent had been obtained.

\section{Data collection}

The period of data collection was from August 2002 to March 2003. Initially, 15 obstetric clinics/hospitals in Tainan City, including six hospitals and nine local clinics, were selected by stratified sampling based on the classification of hospitals and the number of children born. After explaining the purposes and the content of the interview, and obtaining the consent of subjects and their institutes, a semistructured interview covering methods and at what point information is provided and parental consent procedures was conducted and recorded. The parent consent procedures that were examined covered such areas as: how and when they informed parents and obtained parental consent; how much they explained to parents about contents; what reasons they gave for their current practice, and the attitudes and difficulties faced by current NBS services. A total of 22 subjects from the 15 clinics/hospitals were interviewed and each interview lasted 30-40 minutes. For the purposes of the study, the researcher used a clinic/hospital as a unit to combine the 22 interview transcriptions to 15 , and analysed them to discover the process of parental consent currently used in NBS services. Based on this analysis, a structured questionnaire was developed to gather the information from the remaining eight obstetric clinics/hospitals in Tainan City. The staff members who had been recommended by the eight clinics/hospitals completed the open ended questionnaires via telephone interview. This interview focused on the parental consent process of NBS in current practice. Then the self report statements were collected and coded into the different types of parental consent, based on the different categories of NBS.

\section{Data analysis}

In regular debriefing meetings, interview transcripts and relevant documents, such as educational pamphlets about NBS, were used to develop the categories of an analytic framework for the quantitative analysis by content analysis. ${ }^{12}$

Two major domains of the analytic framework were presented as follows. The first dimension, which consists of three categories, was classified by the types of NBS testing and the payment schemes.

\section{Informed consent}

Informed consent was defined as providing relevant information to, and obtaining permission from, parents either in words or through their having signed a letter of authorisation before NBS was conducted.

\section{Informed dissent}

Informed dissent was defined as assent to NBS after being informed where there was an absence of volunteered parental refusal. ${ }^{15}$

\section{No informed consent}

No informed consent was defined as meaning that relevant information had not been provided and consent had not been obtained from parents before NBS was conducted.

Based on the analytic framework, each clinic/hospital was counted as a unit to identify its parental consent types in the three categories of NBS testing.

4. The five traditional genetic/metabolic disorders These disorders can be detected early through NBS and allow prevention or timely treatment to reduce the morbidity and mortality among affected newborns. The government subsidises partial payments of the tests.

\section{Congenital adrenal hyperplasia $(\mathrm{CAH})$}

This newly introduced item in NBS testing is helpful in the early detection of $\mathrm{CAH}$ and its subsequent treatment in affected newborns. Parents must pay all expenses for this test.

\section{Rare metabolic/genetic disorders}

The testing of newborns for rare metabolic/genetic disorders has only recently been introduced into NBS services. It can identify more than 20 rare metabolic disorders simultaneously, including amino acid, organic acid, and fatty acid disorders. For some detectable disorders, there may be no effective/available treatment. Parents must pay the entire testing fee.

The second dimension was categorised according to the subjects' descriptions and existing literature regarding the parental consent procedures for NBS. ${ }^{351314}$

\section{RESULTS}

\section{Characteristics of the information provided by the subjects}

Thirty staff from the 23 obstetric clinics/hospitals were interviewed. These included five obstetricians, 22 nurses, two administrative staff, and one medical technician. All of them had at least two years' work experience. The 23 obstetric clinics/hospitals included one medical centre, four regional hospitals, two district hospitals, and 16 local clinics (table 1).

\section{Parental consent process of NBS}

Data from this study show that the ways of informing parents about consent in current NBS are varied. Usually, staff provided NBS information through pamphlets and/or verbal communication before conducting NBS tests. The most frequently provided information was to do with the type of NBS, the timing of the test (24 hours after the newborn's first feeding), and the payment required for the new tests.

Based on the data contained in the transcripts of the interviews and the questionnaires, the consent models for the three categories of NBS tests in each hospitals/clinics were analysed. These are illustrated in table 2 and were categorised according to the three types of NBS tests as follows:

1. The five traditional genetic/metabolic disorders The most frequently encountered parental consent model in connection with the five traditional genetic/metabolic disorders is "informed dissent" $(60.9 \%)$. This means that the 
Table 1 Characteristics of the information provided by the obstetric hospitals/clinics

\begin{tabular}{|c|c|c|c|}
\hline \multirow[b]{2}{*}{ Variables } & \multirow{2}{*}{$\begin{array}{l}\text { Five traditional } \\
\text { genetic/metabolic } \\
\text { disorders }(n=23) \\
n(\%)\end{array}$} & \multirow{2}{*}{$\begin{array}{l}\begin{array}{l}\text { Congenital adrenal } \\
\text { hyperplasia }(n=23)\end{array} \\
n(\%)\end{array}$} & \multirow{2}{*}{$\begin{array}{l}\text { Rare metabolic/ } \\
\text { genetic disorders } \\
(\mathrm{n}=11) \\
\mathrm{n}(\%)\end{array}$} \\
\hline & & & \\
\hline \multicolumn{4}{|l|}{ Classification of the hospital } \\
\hline Medical centre & $1(4.3)$ & $1(4.3)$ & $1(9.1)$ \\
\hline Regional hospital & $4(17.4)$ & $4(17.4)$ & $3(27.3)$ \\
\hline District hospital & $2(8.7)$ & $2(8.7)$ & $1(9.1)$ \\
\hline Local clinic & $16(69.6)$ & $16(69.6)$ & $6(54.5)$ \\
\hline \multicolumn{4}{|l|}{ Contract newborn screening centre } \\
\hline National Taiwan University & $14(60.9)$ & $14(60.9)$ & $2(18.2)$ \\
\hline Chinese Foundation of Health & $9(39.1)$ & $9(39.1)$ & $9(81.8)$ \\
\hline
\end{tabular}

clinics/hospitals provided the information about NBS and if parents did not express their refusal of the test, they went ahead and conducted this test without parental consent. They did this in the belief that the traditional five item NBS would be beneficial and would not pose any risk to the newborn's health. The subjects of our study thought that in order to ensure that all newborns were screened and all the affected newborns treated in time, the traditional NBS had to be mandatory. Thus the traditional NBS was incorporated into routine paediatric practice in most clinics/hospitals. Accordingly, some clinics/hospitals thought that providing health education and asking for consent from parents would increase costs and also require more manpower. Therefore, $30.4 \%$ of the clinics/hospitals neither provided information nor asked for consent (no informed/consent) before performing this test (table 2).

\section{Congenital adrenal hyperplasia (CAH):}

Based on the analysis of interview transcriptions, CAH was considered to have a high incidence rate and the cost of making treatment available was seen as being compensated for by the relatively inexpensive fee for the test. It was usually treated as an essential and routine screening item and some of the subjects of our study reported that they combined it with the screening for the five traditional genetic/metabolic disorders. Thus, $52.2 \%$ hospitals/clinics chose the "informed dissent" model for CAH screening. Whereas, $30.4 \%$ of the clinics/hospitals used the "no informed/consent" model to save the costs associated with providing information (table 2).

\section{Rare metabolic/genetic disorders}

A total of $45.5 \%$ clinics/hospitals used an "informed consent" model for screening rare disorders because parents must pay a higher price than for any other NBS tests. Plus, $27.3 \%$ of

Table 2 Types of parental consent for different categories of newborn screening

\begin{tabular}{|c|c|c|c|}
\hline \multirow[b]{2}{*}{ Items } & $\begin{array}{l}\text { Five } \\
\text { traditional } \\
\text { genetic/ } \\
\text { metabolic } \\
\text { disorders }\end{array}$ & $\begin{array}{l}\text { Congenital } \\
\text { adrenal } \\
\text { hyperplasia }\end{array}$ & $\begin{array}{l}\text { Rare } \\
\text { metabolic/ } \\
\text { genetic } \\
\text { disorders }\end{array}$ \\
\hline & $n(\%)$ & $n(\%)$ & $n(\%)$ \\
\hline Informed consent & $2(8.7)$ & $4(17.4)$ & $5(45.5)$ \\
\hline $\begin{array}{l}\text { Sign a letter of } \\
\text { quthorisation }\end{array}$ & $0(0.0)$ & $2(8.7)$ & $4(36.4)$ \\
\hline Verbal consent & $2(8.7)$ & $2(8.7)$ & $1(9.1)$ \\
\hline Informed dissent & $14(60.9)$ & $12(52.2)$ & $3(27.3)$ \\
\hline No informed/consent & $7(30.4)$ & $7(30.4)$ & $3(27.3)$ \\
\hline Total & $23(100.0)$ & $23(100.0)$ & $11(100.0)$ \\
\hline
\end{tabular}

clinics/hospitals used the "informed dissent" model. Thus, $72.8 \%$ of clinics/hospitals gave relevant information to parents regarding the test or provided choices before the NBS was conducted. The information the parents were given included the fees for the test and that it was a new screening option. The treatment limitations for some disorders and the possible implications of results for insurance were not mentioned in the educational pamphlets that parents were given.

Using the $\chi^{2}$ test to examine the associations between the classifications of parental consent and the categories of NBS, no significant associations were found between the five traditional disorders and $\mathrm{CAH}\left(\chi^{2}=0.82, \mathrm{p}=0.66\right)$, and between $\mathrm{CAH}$ and rare disorders $\left(\chi^{2}=2.29, \mathrm{p}=0.19\right)$. A significant difference was shown, however, between the five traditional disorders and rare disorders $\left(\chi^{2}=6.59, \mathrm{p}=0.04\right)$.

\section{ANALYSING THE RESULTS}

The process of obtaining parental consent was inconsistent across the different categories of NBS. The requirements needed to ensure that there was a proper informed consent process, which emphasises the importance of providing information as a prerequisite to testing, were not met. ${ }^{3}{ }^{10}$ Even if one accepts that the ethical criteria relating to the informed consent process for NBS are different from those relating to general genetic testing, informing before testing is required. ${ }^{510}$ Providing the information necessary for an informed consent would enhance parental concepts of NBS, would respect the parents' right to know and to choose, and would decrease the psychosocial impact of a positive test result. ${ }^{12}$ If, for example, parents have not been informed about the meaning of screening, when they receive a positive NBS test result, they will believe that their baby has a disease and will have a more emotional response and/or suffer more negative effects. Moreover, fulfilling the requirements for the processes of informed consent would not only educate parents and thereby improve their understanding and make it more likely for them to give permission for NBS, it would also permit them to share in decision making and increase their adherence to recommendations for further testing and follow up. ${ }^{361617}$ Any request for informed consent must be preceded by adequate information about the purpose and possible outcomes of the screening, the benefits and risks of the screening procedure, and choices that might have to be made. $^{5}{ }^{10}$

Although early studies of NBS in the US showed that the cost and time involved in NBS did not appear to be prohibitive, ${ }^{3}$ several clinics/hospitals in this study expressed the opinion that talking to parents and asking for permission to conduct NBS would be time consuming and costly. Accordingly, they were reluctant to inform parents before conducting NBS. In this study, 27.3-30.4\% of clinics/hospitals 
adhere to a "no informed/consent" model in each category of NBS. It is necessary, however, to provide full information to parents for any NBS tests. ${ }^{9}$ The American Academy of Pediatrics suggests parents should be informed about NBS during the prenatal period, since this increases the efficiency of the provision of information. ${ }^{3}$

Because of the new technologies, such as Tandem MS for rare metabolic/genetic disorders, NBS possibilities have expanded. In this study, over half the hospitals/clinics studied did not adhere to an "informed consent" model for screening rare metabolic/genetic disorders, and the information provision rarely included the treatment limitations. Hence, the way most NBS is currently conducted is in conflict with basic ethical principles. Because the clinics/hospitals staff lacked the knowledge and skills to explain Tandem MS and rare metabolic/genetic disorders, they were concerned about time consuming and difficult questions from parents, such as those to do with the pathology or treatment of the disease. However, sharing decision making is particularly important when the safety and effectiveness of some NBS tests are still being evaluated, and there may be ethical, legal, and social implications of failing to obtain consent for this category of NBS. ${ }^{1-468}$ Moreover, when this screening does not meet the criteria for treatable or early onset diseases, but only informs couples about their future reproductive risks and does not benefit the affected newborn, explicit parental consent is required. ${ }^{13469}$ Thus it is critical to design and implement in service training about new NBS items for staff of clinics/hospitals to enhance their ability to explain relevant information to parents.

In addition, NBS authority in Taiwan derives from the genetic health law, which aims to protect newborns' health. It still lacks a legal defence for the absence of explicit parental consent for NBS, especially for the new items.' Specific legislation to regulate the informed consent process for NBS, which would fulfil the essential criterion of ensuring parental rights, should be established. Whether or not any category of NBS should be voluntary or mandatory, informing parents before screening is necessary to respect the parental right to know and parental autonomy.

\section{CONCLUSIONS}

Newborn screening is the only type of genetic screening that does not require the obtaining of parental consent; however, providing appropriate information is still indispensable before conducting NBS. ${ }^{3}{ }^{10}$ In Taiwan, because the traditional NBS has been carried out for many years, clinical staff have become accustomed to treating NBS as routine practice. Therefore, they see all forms of NBS, even the new ones, as being the same. The main reason for increasing the percentage of informed consent for screening for rare metabolic/genetic disorders has more to do with concerns about payment than with ethical issues. Accordingly, there is much room for improvement.

The model of informed consent for parents whose children are undergoing NBS should be established on a sound ethical basis, which respects the parental right to know and decreases the psychosocial impact and negative influence of a positive test result. Further studies need to investigate parental responses to the current consent process of NBS. Understanding parental demands for information related to NBS, parental attitudes toward the consent process, and the psychosocial impact of NBS on parents is essential if a new parental consent model for NBS is to be developed.

\section{ACKNOWLEDGEMENTS}

This study was supported by the National Research Program for Genome Medicine of the Ethical, Legal and Social Implications Group of the National Science Council of Taiwan (NSC91-3112-H-006-006). The authors thank the staff of the 23 clinics/hospitals in Tainan City who provided such valuable information and we also thank Christopher Waters who edited this paper.

\section{Authors' affiliations}

M-C Huang, C-K Lee, Department of Nursing, National Cheng Kung

University, Tainan, Taiwan, ROC

S-J Lin, Department of Pediatrics, National Cheng Kung University and Hospital, Tainan, Taiwan, ROC

I-C Lu, Department of Nursing, Chung Hwa College of Medical

Technology, Tainan, Taiwan, ROC

\section{REFERENCES}

1 Ross LF. Genetic services for children: who should consent? In: Mahowald M, McKusick V, Scheuerle A, et al. Genetics in the clinic: clinical, ethical, and social implications for primary care. St Louis, MO: Mosby, 2001:167-79.

2 McQueen M. Some ethical and design challenges of screening programs and screening tests. Clinica Chimica Acta 2002;315:41-8.

3 American Academy of Pediatrics. Serving the family from birth to the medical home. Newborn screening: a blueprint for the future-a call for a national agenda on state newborn screening programs, Pediatrics 2000; 106:389-423

4 Ross LF, Moon MR. Ethical issues in pediatric genetics. In: Mahowald M, McKusick V, Scheuerle A, et al. Genetics in the clinic: clinical, ethical, and social implications for primary care. St Louis, MO: Mosby, 2001:153-66.

5 Committee on Bioethics. Ethical issues with genetic testing in pediatrics. Pediatrics 2001;107:1451-5.

6 Lloyd-Puryear MA, Forsman I. Newborn screening and genetic testing. J Obstet Gynecol Neonatal Nurs 2002;31:200-7.

7 Fost N. Ethical issues in genetics. Pediatr Clin North Am 1992;39:79-89.

8 Wildeman S, Downie J. Genetic and metabolic screening of newborns: must health care providers seek explicit parental consent? Health Law Journal 2001; 9:61-111.

9 Huang M-C, Lin S-J. Newborn screening: should explicit parental consent be required? Acta Paediatric Taiwanica 2003;44:126-9.

10 World Health Organisation. Proposed international guidelines on ethical issues in medical genetics and genetic services, WHO Meeting on Ethical Issues in Medical Genetics. Geneva: World Health Organisation, 1997 http://www.who.int/genomics/publications/en/ethicalguidelines 1998.pdf (accessed 14 Apr 2005)

11 Department of Health of Taiwan. VII. Health promotion and protection: 2) Genetic health, Taiwan public health report 2003, Taipei: Department of Health 2003:50. http://www.doh.gov.tw/ufile/doc/arteck/48.pdf (accessed 14 Apr 2005).

12 Weber RP. Basic content analysis [2nd ed]. London: Sage, 1990.

13 Altonn H. Isle newborn screening finds rare baby defect: undetected, the disorder could cause serious illness, leading to a coma and death, 2002. http://starbulletin.com/2002/11/25/news/story3.html laccessed $14 \mathrm{Apr}$ 2005).

14 Committee on Bioethics. Informed consent, parental permission, and assent in pediatric practice. Pediatrics 1995;95:314-17.

15 Pass KA. Lessons learned from newborn screening for phenylketonuria. In: Khoury MJ, Burke W, Thomson EJ, eds. Genetics and public health in the 21 st century. New York: Oxford, 2000:392-5.

16 Thompson JE, Thompson HO. A bioethical decision model. Professional ethics in nursing. Florida: Krieger, 1990.

17 Chadwick R, ten Have H, Husted J, et al. Genetic screening and ethics: European perspectives. J Med Philos 1998;23:255-73. 